\title{
Fragmentation vs rearrangement of the amide and thioester groups in 4,4-disubstituted cyclohexadienones
}

\author{
John N. Marx* and Howard M. Merken \\ Department of Chemistry and Biochemistry, Texas Tech University, Lubbock, TX 79409-4061 \\ E-mail: john.marx@ttu.edu
}

\author{
Dedicated to Professor Henry J. Shine on the Occasion of his $80^{\text {th }}$ Birthday \\ (received 24 Jun 03; accepted 14 Feb 04; published on the web 26 Feb 04)
}

\begin{abstract}
Migration of electron-withdrawing substituents in carbocations normally occurs in preference to other common substituents that are normally very good migrating groups, if the electronwithdrawing group contains a $\pi$ bond. This study represents the first investigation of the amide (diethylamido) and thioester (thiocarbethoxy) substituents in the dienone-phenol rearrangement reaction. In aqueous acid, the dienones $\mathbf{6 b}$ and $\mathbf{6 c}$ were found to fragment instead of to undergo rearrangement. A mechanistic rationalization is given.
\end{abstract}

Keywords: Cyclohexadienones, carbocation rearrangements, carbocation fragmentations, electron-withdrawing substituents

\section{Introduction}

Rearrangement via 1,2- shifts in carbocations is a very common phenomenon that has been studied extensively ${ }^{1,2}$. Predicting which substituent will migrate when there is a competition between two similar groups can be difficult. The results of such studies are usually expressed as relative migratory aptitudes (RMA), which describe which group migrates in preference to another one. Thus, this is an intramolecular comparison method. The RMAs can vary substantially with the migrating system, since a number of variables can come into play in defining the transition state(s) for the migration.

A superior method to describe the migration in such rearrangement reactions was developed by Stiles and Meyer $^{3}$ in 1959. This method, which gives values termed migration tendencies (MT), is an intermolecular comparison, defined as $\mathrm{MT}=\mathrm{k}_{\mathrm{p}}{ }^{\mathrm{R}} / \mathrm{k}_{\mathrm{p}}{ }^{\mathrm{R}}$, where $\mathrm{R}$ is the migrating group and $\mathrm{R}$ ' is the group remaining behind, which is held constant, usually as methyl, for the series of compounds under study, and $\mathrm{k}_{\mathrm{p}}$ is the partial rate constant for the migration, corrected 
by calculation to $100 \%$ cation concentration. In this method, in properly chosen systems, the MT values reflect properties of the migrating group $\mathrm{R}$, since all other variables are held constant.

We have had considerable success in predicting not only which group will migrate but also in rationalizing relative rates of such migrations, using the MT concept $\mathrm{t}^{4-8}$. Of special interest in our work is the situation in which an electron-withdrawing substituent, such as an ester, is placed in competition with a substituent that is normally a very good migrating group, as represented schematically in Figure 1.

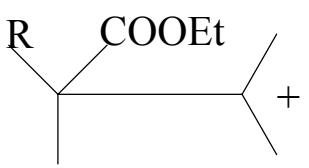

1

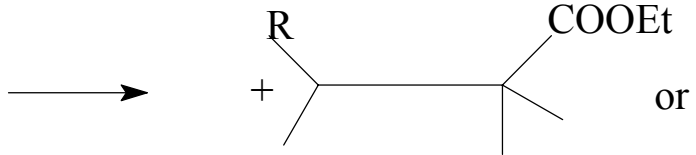

2

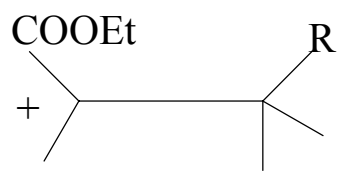

3

Figure 1. Migratory competition in cations between two substituents where one is electronwithdrawing.

A simplistic interpretation suggests that the electron-withdrawing group, COOEt, should not migrate, since it is called upon to stabilize positive charge density in the transition state, and it is adversely polarized for this task. However, there are two major factors that determine which group migrates. The first ${ }^{4,9,10}$ is the fact that if the electron-withdrawing group does not migrate, it is called upon to stabilize the positive charge placed $\alpha$ to an electron-withdrawing group in the transition state $\mathbf{4}$ and thus in the product ion $\mathbf{3}$.

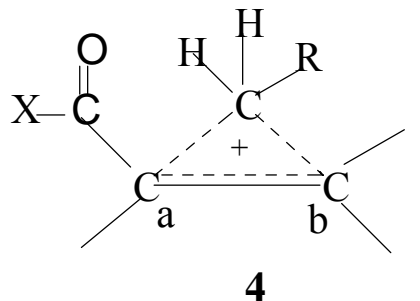

4

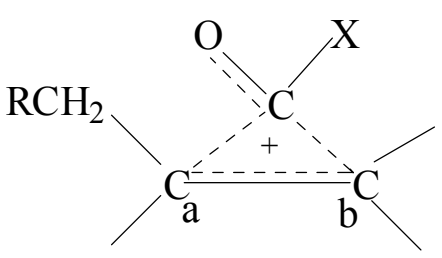

5

a. $\mathrm{X}=\mathrm{OEt}$

b. $X=$ SEt

c. $\mathrm{X}=\mathrm{NEt}_{2}$

Figure 2. Transition states for alkyl group migration vs. electron-withdrawing group migration.

The second major factor that controls this type of rearrangement process is the inherent ability of the electron-withdrawing substituent to migrate. Our data ${ }^{4-8}$ clearly show that the $\pi$ bond in the carbonyl group, although it is polarized adversely to stabilize positive charge, nevertheless provides resonance stabilization for transition states like 5. Evidence to support this includes a) a trichloromethyl group, although it has about the same polarity as an ester group, absolutely does not migrate $^{6}$; b) the vinyl group migrates about 1000 times faster than the ester in the dienone system ${ }^{7}$, since both groups have a $\pi$ bond but only the ester is affected by adverse 
polarity; c) the vinyl group migrates $c a .200$ times faster than an ethyl group in the dienone system $^{7}$; d) the ester migrates much faster in a dienone system (4-methoxy-4-substitutient-2,5cyclohexadienone) which forces more positive charge density on the migrating group than it does in a system where the charge is more distributed over the rest of the system and is thus less on the ester, demonstrating that the $\pi$ bond can donate more stabilization in systems where it is more necessary for it to do $\mathrm{so}^{8}$, and e) more recent ab-initio MO calculations of acyl group migration in a rigid 7-oxabicyclo[2.2.1] heptyl cationic system are in experimental agreement with migrational ability and are attributed to a favorable hyperconjugative interaction of the carbonyl group ${ }^{11}$.

Based upon these principles, we predicted that other electron-withdrawing groups similar to the ester would migrate at substantially different rates in the same migrating system. The current work reports an attempt to verify this prediction experimentally. Comparison of the transition states for ester, $\mathbf{5 a}$, thioester, $\mathbf{5 b}$, and amide, $\mathbf{5} \mathbf{c}$ suggests that if the substituent $\mathrm{X}$ is more electron-donating, it should donate more electron density by resonance to the carbonyl group. This would decrease the effect of the $\pi$ bond in back-donating electron density to the rest of the system, decreasing the over-all stability of the rearrangement transition state. This predicts that the order of rate of rearrangement, as measured by MT values, should be in the order: $\mathbf{5 b}>\mathbf{5 a}>\mathbf{5 c}$, i.e. the order of rearrangement rates should be thioester $>$ ester $>$ amide.

Similar rearrangement studies have been carried out in an epoxide system. Using $\mathrm{BF}_{3} \mathrm{OEt}_{2}$ as the catalyst, qualitative observations suggested that the thioester group ${ }^{12,13}$ migrated substantially faster than the ester in that system, but the amide was very sluggish and refused to rearrange at all except for a small amount in one compound ${ }^{14}$.

The 4-methyl-4-substituent-2,5-cyclohexadienone system, $\mathbf{6}$, was chosen for this study, since this is the parent system for the dienone-phenol rearrangement, and the ester has already been substantially studied in this system. More importantly, quantitative studies to measure the MT values of the amide and thioester substituents could then be done.

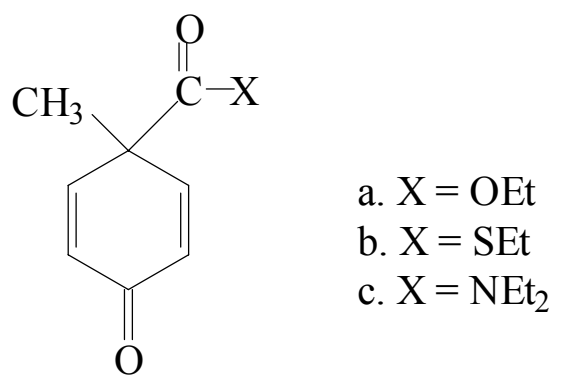

6

Figure 3. Compounds used for the rearrangement studies. 


\section{Results and Discussion}

The syntheses of 4-methyl-4-thiocarbethoxy-2,5-cyclohexadienone, $\mathbf{6 b}$, and 4-methyl-4diethylamido-2,5-cyclohexadienone, 6c, were first attempted via transformations from the readily available ${ }^{4} 4$-methyl-4-carbethoxy-2-cyclohexenone, 7a. Direct treatment of ester $7 \mathbf{a}$ with diethyl amine under heat and pressure gave recovered starting material. Attempted hydrolysis of the ester to the acid under vigorous saponification conditions gave either starting material or complex mixtures of degradation products. This was assumed to be due to a steric problem resulting from operating at a neopentyl-type position. However, reaction of $7 \mathbf{a}$ with $\mathrm{LiAlH}_{4}$ gave reduction to the corresponding diol, which could be re-oxidized slowly but cleanly with chromic acid (Jones reagent) to the enone acid $\mathbf{7 b}$. However, attempts to activate the acid as the acid chloride, 7c, the imidazole derivative, or via use of dicyclohexylcarbodiimide or other coupling agents with diethyl amine failed, again presumably for steric reasons.

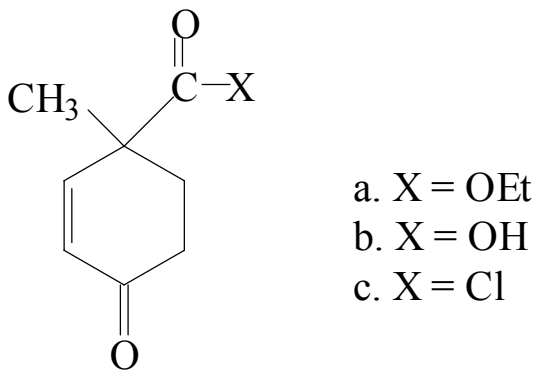

7

Figure 4. Possible precursors to synthesize dienones 6.

The dienones $\mathbf{6 b}$ and $\mathbf{6 c}$, however, could both be made via the procedure in Scheme 1, utilizing Danishefsky's diene ${ }^{15}, \mathbf{8}$, and methacroyl chloride, 9. The resulting Diels-Alder adduct 10 was treated, without isolation, either with sodium ethyl thiolate and acid hydrolysis to give the enone thioester $\mathbf{1 1}$ or with diethyl amine and then acid hydrolysis, to give the enone amide 12. These compounds were converted into the dienones $\mathbf{6 b}$ or $\mathbf{6 c}$ by the selenoxide elimination method $^{16}$. 


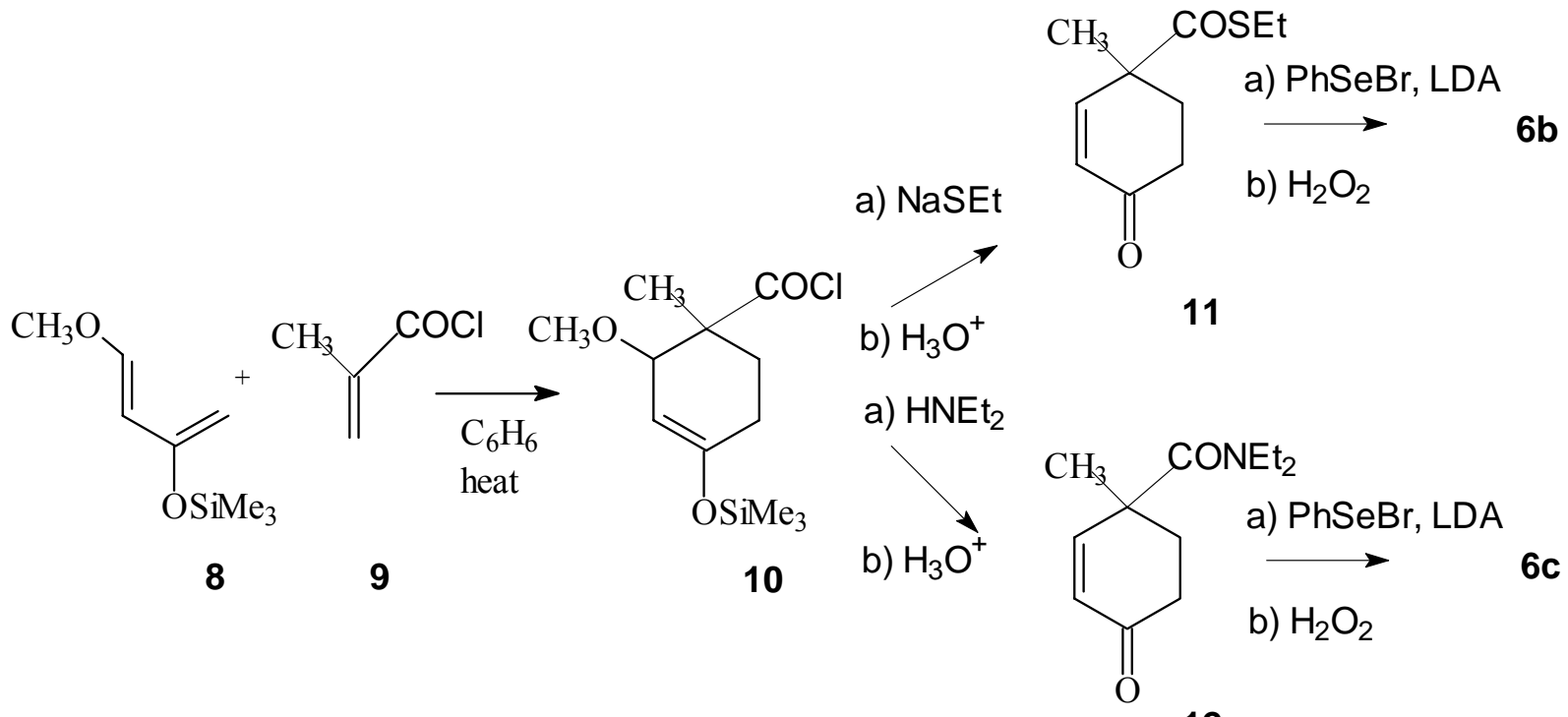

12

Scheme 1. Synthesis of the dienones $\mathbf{6 b}$ and $\mathbf{6 c}$.

Rearrangement reactions of $\mathbf{6 b}$ and $\mathbf{6 c}$ were carried out in aqueous $\mathrm{H}_{2} \mathrm{SO}_{4}$, as in our previous studies $^{4-8}$. The rates of the reactions were very fast, as recorded in Table 1. By comparison, the carbethoxy compound 6a rearranged too slowly to measure under these conditions and required ca. $50 \% \mathrm{H}_{2} \mathrm{SO}_{4}$ to rearrange at the slowest rate which was practical to measure ${ }^{2,8}$.

Table 1. Kinetics of fragmentation of dienones $\mathbf{6 b}$ and $\mathbf{6 c}$

\begin{tabular}{ccc} 
Compound & $\% \mathrm{H}_{2} \mathrm{SO}_{4}$ & $\mathrm{k}_{\mathrm{obs}}\left(\mathrm{sec}^{-1} \times 10^{3}\right)$ \\
$\mathbf{6 b}$ & 17.9 & 10.9 \\
$\mathbf{6 b}$ & 20.4 & 171.0 \\
$\mathbf{6 c}$ & 17.9 & 1.31 \\
$\mathbf{6 c}$ & 20.4 & 1.91 \\
\hline
\end{tabular}

However, product studies revealed that these rates, which measure the disappearance of the starting materials, were due to a cleavage reaction. The only aromatic product detected was $\mathrm{p}$ cresol. Cleavage also occurred at higher acid concentrations, investigated for $6 \mathrm{c}$ up to ca. 35\% $\mathrm{H}_{2} \mathrm{SO}_{4}$, where the kinetics were near the fast end of the experimentally accessible range via UV analysis. Dienone $\mathbf{6 b}$ fragmented about 85 times faster than dienone 6c (Table 1). 
In the dienone system, rearrangement is very favorable under most cases, but other cases are known where fragmentation occurs under acid catalysis. In fact, the carbethoxy group in $\mathbf{6 a}$ undergoes some fragmentation in aqueous acid. For example, in $45 \% \mathrm{H}_{2} \mathrm{SO}_{4}, 21 \%$ rearrangement and $79 \%$ fragmentation occurred, whereas in $70.4 \% \mathrm{H}_{2} \mathrm{SO}_{4}, 68 \%$ rearrangement and $32 \%$ fragmentation occurred ${ }^{8}$. Thus, the carbethoxy dienone $6 \mathbf{a}$ is poised on the mechanistic boundary, where the rates of rearrangement and fragmentation are similar. Fortunately, the MT value of the ester can be calculated validly, since only $\mathrm{k}_{\mathrm{p}}$ (partial rate constants for rearrangement) are used in the determination. The ketone group in 4-methyl-4-acetyl-2,5cyclohexadienone undergoes only fragmentation ${ }^{17}$. The carboxylic acid group undergoes easy fragmentation. Now the amide and the thioester groups can be added to this short list of fragmenting substituents.

There are two possible mechanisms for the cleavage, shown in Scheme 2. Path a involves hydrolysis followed by easy cleavage of the carboxylic acid. Path $b$ is a direct fragmentation via an acylium ion. Path $\mathrm{c}$ shows the competing rearrangement pathway.<smiles>[X]C(=O)C1(C)C=CC(=O)C=C1</smiles><smiles>[X]C(=O)C1(C)C=CC(=O)C=C1</smiles>

6

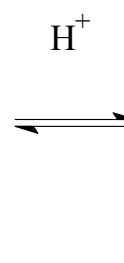

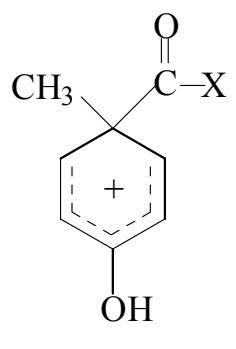

17

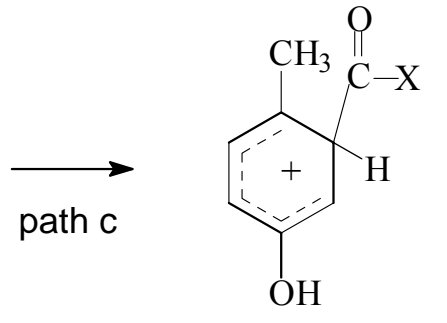

18<smiles>[X]C(=O)c1cc(O)ccc1C</smiles>

19

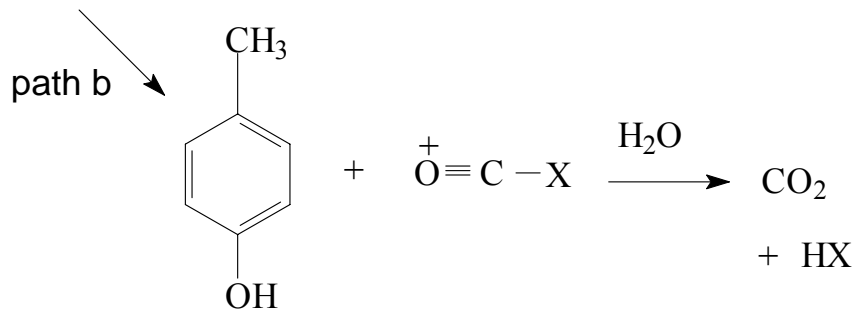

16

Scheme 2. Mechanistic pathways for rearrangement vs. cleavage in the dienone system. 
Fragmentation via an acylium ion (path b) is much more reasonable than hydrolysisdecarboxylation (path a) for the following reasons: a) NMR analysis of these compounds, carried out in $\mathrm{H}_{2} \mathrm{SO}_{4}$ or in $\mathrm{CF}_{3} \mathrm{COOH}$ solution shows that protonation is dramatically favored at the dienone carbonyl instead of the 4-substituent. The vinylic H's are deshielded in 6a by ca. 1.0 and $1.3 \mathrm{ppm}$ respectively when fully protonated, whereas the $\mathrm{CH}_{2}$ of the ester is not deshielded at all ${ }^{4}$, compared to values in $\mathrm{CDCl}_{3} ; \mathrm{b}$ ) the enone precursors $\mathbf{1 1}$ and $\mathbf{1 2}$ are stable to the acid conditions used; c) hydrolysis of enone ester 7a could not be accomplished under vigorous saponification conditions due to the sterically hindered nature of the carbonyl in these compounds, as mentioned above; d) the amide is expected to be much less reactive than the ester and especially the thioester in the hydrolysis pathway, but it reacts much more rapidly in the cleavage pathway than does the ester and nearly as fast as the thioester; e) the nitrogen in the amide stabilizes its acylium ion a great deal by resonance, making the observed cleavage reactivity of the amide reasonable.

It is instructive to compare the results in the dienone system to those reported by others in the epoxide systems. Wemple ${ }^{12,13}$ has reported transformations of compounds 20, in which the thioester group migrated in preference to $\mathrm{R}=$ methyl or hydrogen. Wemple's group has also reported the rearrangement of compound 22 ( $\mathrm{R}=$ methyl), in which there was $20 \%$ amide migration and $80 \%$ methyl migration. Several other related compounds with amide substituents showed no amide migration ${ }^{14}$.

House $^{9}$ has reported results with epoxides in which the ketone is the migrating group. In the series 23, where the benzoyl group is in migratory competition with $\mathrm{R}=$ methyl, ethyl, and phenyl groups, the relative migratory aptitude (RMA) was found to be methyl $<$ ethyl $<$ benzoyl $<$ phenyl. Again, no cleavage occurred.
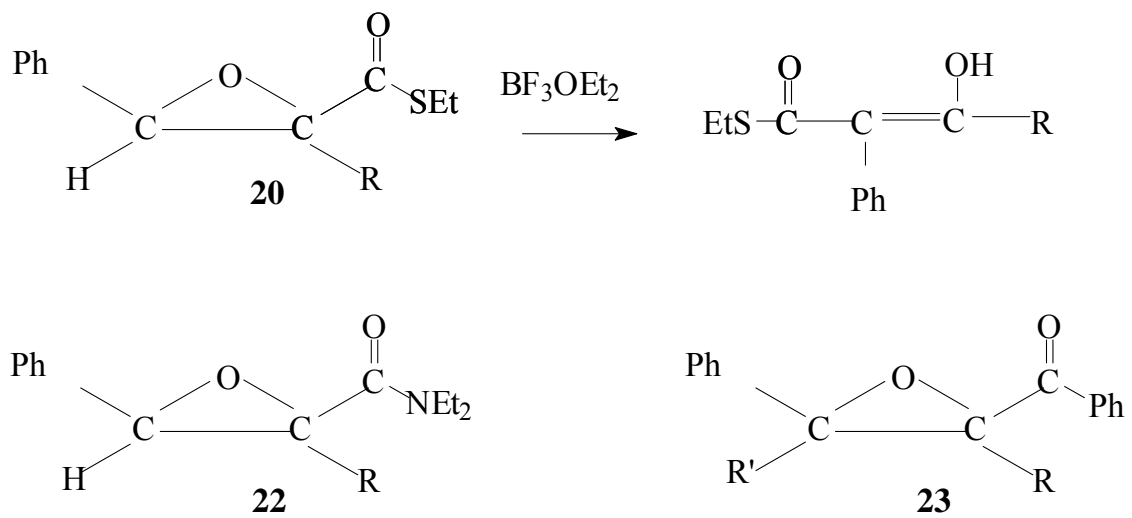

Figure 5. Epoxides with electron-withdrawing groups that migrate under acid catalysis.

Thus, it is clear that the epoxides (pinacolic-type systems) are more subject to rearrangement and the dienones are more subject to cleavage when electron-withdrawing groups are placed in migratory competition in these easily rearranging systems. This can be explained by the fact that 
there is substantially less positive charge build-up in the epoxide and pinacol systems in the transition state, so the migrating group which is adversely polarized is not called upon to stabilize the charge as much and enjoys a greater freedom to migrate. In the highly delocalized systems, in which an aromatic product results, such as in dienones, dienols ${ }^{2}$, and some heterocyclic systems ${ }^{18}$, the balance between cleavage and rearrangement is tipped much more toward the cleavage. This suggests that the transition state (using the ester as the example), which can be considered as a resonance-stabilized structure, has structure a (Figure 6) as the major contributor. This is exactly the type of structure that could fragment to an acylium ion, since the $\pi$ system can act as a very good "leaving group" when it is an aromatic ring instead of an alkene. Hammett studies on related phenyl esters ${ }^{19}$ are in accord with very substantial acylium ion character in the transition state for the rearrangement reaction.

Resonance structures b and c simply say that positive charge density is delocalized substantially on the migration origin and the migration terminus. The extreme form $\mathbf{d}$, on the other hand, although it suggests that the oxygen of the carbonyl is a destabilizing force, cannot be a meaningful contributor to the over-all stability of the transition state.
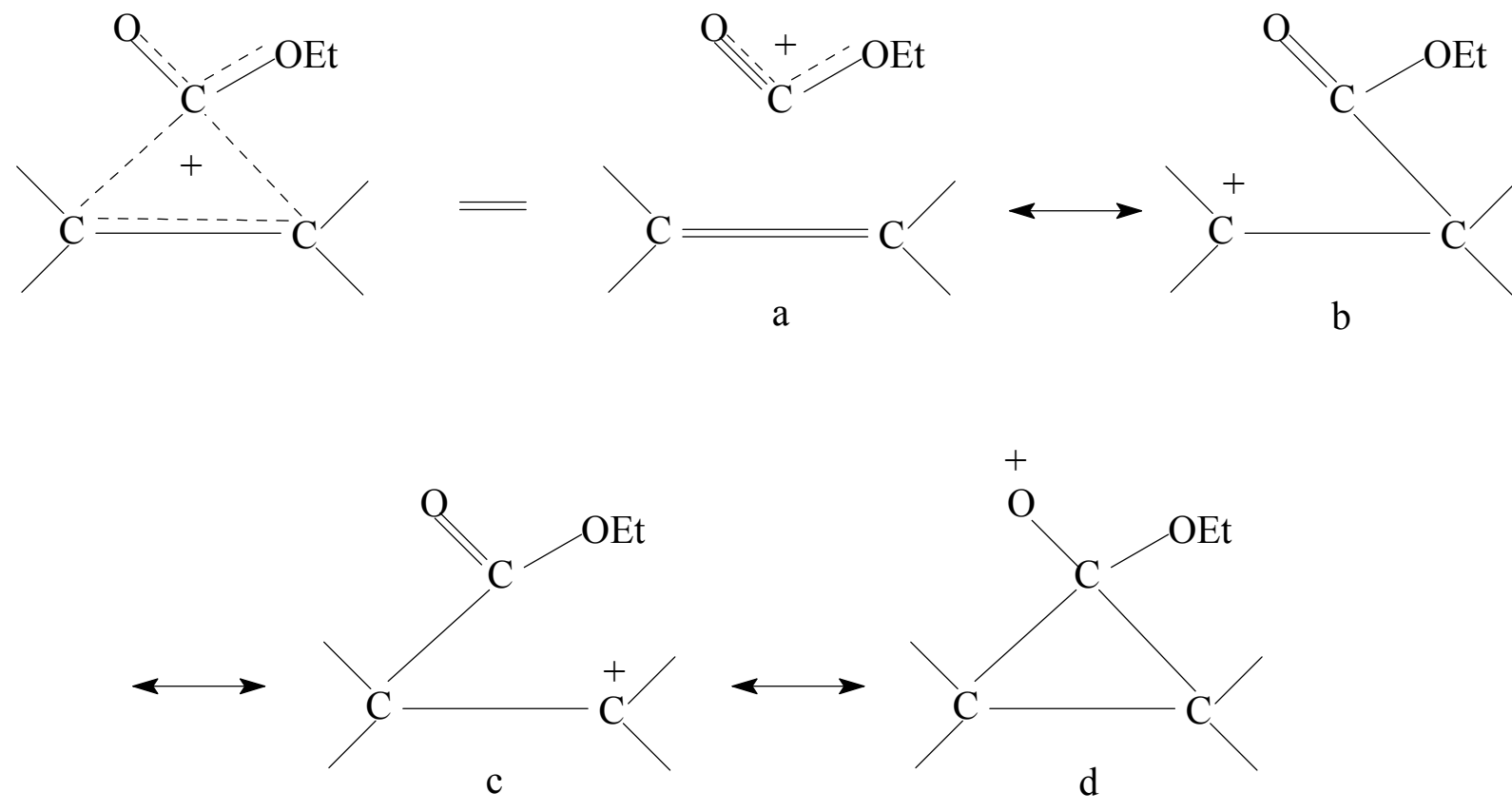

Figure 6. Resonance forms for the transition state, using the ester example.

\section{Acknowledgements}

Financial support by the Robert A Welch foundation, Houston, TX, Grant D-1140, is gratefully acknowledged. 


\section{Experimental Section}

General Procedures. NMR spectra were run on an IBM AF-200 spectrometer, at $200 \mathrm{MHz}$ for ${ }^{1} \mathrm{H}$ and $50 \mathrm{MHz}$ for ${ }^{13} \mathrm{C}$. IR spectra were recorded on a Perkin-Elmer $1600 \mathrm{FTIR}$ spectrometer. ChemAnalytics, Tempe, AZ, determined elemental analyses. Column chromatography was conducted on a $20 \mathrm{~mm}$ diameter glass column packed with EM Science 60-200 mesh silica gel to ca. $150 \mathrm{~mm}$ depth. The column was eluted with varying ratios of ethyl ether in $35-60^{\circ}$ petroleum ether, collecting $20 \mathrm{~mL}$ fractions and combining like fractions on the basis of tlc or NMR spectra. Kinetics were determined with a Shimadzu UV-VIS Recording Spectrophotometer, Model UV-265. The temperature was controlled by a Masterline Forma Scientific 2095 Bath \& Circulator, held at $25+-0.2{ }^{\circ} \mathrm{C}$. The slopes of the plots of the absorbance vs. time were used to obtain the rate constants, which had an R factor of $0.996-0.998$ over at least 4 half-lives.

4-Methyl-4-thiocarbethoxy-2-cyclohexenone (11). To $25 \mathrm{ml}$ of dry benzene under $\mathrm{N}_{2}$ was added by syringe trans-1-methoxy-3-trimethylsiloxy-1,3-butadiene (Danishefsky's diene, 1.60 $\mathrm{mL}, 8.22 \mathrm{mmol})$ and then methacryloyl chloride $(0.80 \mathrm{~mL}, 8.19 \mathrm{mmol})$ and the solution refluxed $24 \mathrm{~h}$. After cooling, sodium ethyl thiolate $(842 \mathrm{mg}, 10.0 \mathrm{mmol})$ was added and the mixture was refluxed $1 \mathrm{~h}$. Ether was added, the organic layer was washed with water, dried with $\mathrm{MgSO}_{4}$, and solvents evaporated. To the crude product was added $25 \mathrm{~mL}$ of a $50: 50$ mixture of $5 \% \mathrm{HCl}$ :THF. This mixture was stirred at $25{ }^{\circ} \mathrm{C}$ for $1 \mathrm{~h}$, and then worked up by the ether method. The product was purified by chromatography through silica gel, using fractions starting with $10 \%$ ether in petroleum ether and increasing the amount of ether. The $20 \%$ ether fractions were combined to yield $351 \mathrm{mg}(1.77 \mathrm{mmol}, 21.6 \%)$ of $\mathbf{1 1}$ as a colorless heavy oil, further purified by short path vacuum distillation (bath $\left.230^{\circ}, 0.1 \mathrm{~mm}\right)$. NMR data: $\delta \mathrm{H}\left(\mathrm{CDCl}_{3}\right) 6.87(\mathrm{~d}, \mathrm{~J}=10.3 \mathrm{~Hz}, 1 \mathrm{H})$; $6.05(\mathrm{~d}, \mathrm{~J}=10.3 \mathrm{~Hz}, 1 \mathrm{H}), 2.89$ (q, J = 7.4 Hz, $2 \mathrm{H}), 2.4(\mathrm{~m}, 2 \mathrm{H}), 1.9(\mathrm{~m}, 2 \mathrm{H}), 1.41,(\mathrm{~s}, 3 \mathrm{H})$, $1.24(\mathrm{t}, \mathrm{J}=7.4 \mathrm{~Hz}, 3 \mathrm{H})$. Anal. Calcd. for $\mathrm{C}_{10} \mathrm{H}_{14} \mathrm{O}_{2} \mathrm{~S}: \mathrm{C}, 60.58 \%$; H, 7.12\%; $\mathrm{S}, 16.17 \%$. Found: C, $60.37 \%$; H, 7.22\%; S, 16.21\%.

4-Methyl-4-thiocarbethoxy-2,5-cyclohexadienone (6b). Lithium diisopropyl amide (LDA, 1.8 $\mathrm{M}$ in THF, $0.66 \mathrm{~mL}, 1.2 \mathrm{mmol}$ ) was added to $1.5 \mathrm{~mL}$ dry THF and cooled to $-78{ }^{\circ} \mathrm{C}$. A portion of 11 (200 mg, $1.01 \mathrm{mmol})$ in $1.0 \mathrm{ml}$ dry THF was added dropwise via syringe and stirred for 1 $\mathrm{h}$, then the cooling bath was removed and stirring continued for $0.5 \mathrm{~h}$. The product was extracted with ether to yield $513 \mathrm{mg}$ of a mixture of diphenyl diselenide and S-ethyl 1-methyl-4-oxo-3phenylseleneno-1-cyclohex-2-ene thiocarboxylate. Complex NMR signals for two diastereomers were detected, with diagnostic peaks at $\delta 4.4 \& 4.0$ (dd, $0.5 ; \mathrm{H}$ each). Treatment of this crude product in $20 \mathrm{~mL}$ of $\mathrm{CH}_{2} \mathrm{Cl}_{2}$ at $0{ }^{\circ} \mathrm{C}$ with $120 \mu \mathrm{l}$ of $30 \% \mathrm{H}_{2} \mathrm{O}_{2}(1.17 \mathrm{mmol})$ and stirring $0.5 \mathrm{~h}$ and then $1 \mathrm{~h}$ at $25{ }^{\circ} \mathrm{C}$ gave dienone $\mathbf{6 b}$ mixed with diphenyl disulfide. Chromatography gave the dienone 6b (95.9 mg, $0.49 \mathrm{mmol}, 48.4 \%)$. NMR data: $\delta \mathrm{H}\left(\mathrm{CDCl}_{3}\right) 6.94(\mathrm{~d}, \mathrm{~J}=10.2 \mathrm{~Hz}, 2 \mathrm{H})$, 
$6.37(\mathrm{~d}, \mathrm{~J}=10.2 \mathrm{~Hz}, 2 \mathrm{H}), 2.85(\mathrm{q}, \mathrm{J}=7.4 \mathrm{~Hz}, 2 \mathrm{H}), 1.52(\mathrm{~s}, 3 \mathrm{H}), 1.21(\mathrm{t}, \mathrm{J}=7.4 \mathrm{~Hz}, 3 \mathrm{H}) . \delta \mathrm{C}$ $\left(\mathrm{CDCl}_{3}\right)$ 196.9, 184.7, 148.4, 130.3, 56.0, 24.1, 23.7, 14.2. IR data. cm-1 (film), 3042, 2974, 2932, 2874, 1662, 1627, 1602, 1451, 1414, 1251, 1110, 974, 923, 865, 821, 766, 733, 700, 658, 618. Anal. Calcd. for $\mathrm{C}_{10} \mathrm{H}_{12} \mathrm{O}_{2} \mathrm{~S}: \mathrm{C}, 61.20 \% ; \mathrm{H}, 6.16 \% ; \mathrm{S}, 16.34 \%$. Found: $\mathrm{C}, 61.39 \%$; $6.32 \% ; \mathrm{S}, 16.31 \%$.

$\mathrm{N}, \mathrm{N}$-Diethyl 1-methyl-4-oxo-2-cyclohexenecarboxamide (12). The procedure used to synthesize 11 was followed, using $1.00 \mathrm{~mL}$ of Danishefsky's diene and $0.50 \mathrm{~mL}$ of methacryloyl chloride and using $2.39 \mathrm{ml}$ of diethylamine in place of the sodium ethyl thiolate. The crude product was isolated as before. The enone amide, 12, was found in the $40 \%-60 \%$ ether/petroleum fractions (554 mg, $2.65 \mathrm{mmol}, 51.6 \%$ ), further purified by short path vacuum distillation (bath $230^{\circ}, 0.1$ mm). NMR data: $\delta \mathrm{H}\left(\mathrm{CDCl}_{3}\right) 6.97(\mathrm{~d}, \mathrm{~J}=10.2 \mathrm{~Hz}, 1 \mathrm{H}), 5.93(\mathrm{~d}, \mathrm{~J}=10.2 \mathrm{~Hz}, 1 \mathrm{H}), 3.34$ (2 closely overlapping quartets, $\mathrm{J}=7.0 \mathrm{~Hz}, 4 \mathrm{H}), 2.5(\mathrm{~m}, 2 \mathrm{H}), 2.0(\mathrm{~m}, 2 \mathrm{H}), 1.45(\mathrm{~s}, 3 \mathrm{H}), 1.11(\mathrm{t}, \mathrm{J}$ $=7.0 \mathrm{~Hz}, 6 \mathrm{H}$ ). Anal. Calcd. for $\mathrm{C}_{12} \mathrm{H}_{19} \mathrm{NO}_{2}$ : C, 68.87\%; H, 9.15\%; N, 6.69\%. Found: C, $68.64 \%, \mathrm{H}, 9.05 \%$, N, 6 65\%.

$N$, $N$-Diethyl 1-methyl-4-oxo-cyclohexa-2,5-dienecarboxamide (6c). Phenylselenenylation of compound 12 proceeded similarly to that for compound $\mathbf{1 1}$ described above. Chromatography of the product on silica gel gave the desired product in the $50 \%$ ether in petroleum ether fractions to give 6c (79.4 mg, $0.383 \mathrm{mmol}, 17.1 \%), \mathrm{mp} \mathrm{87-89}{ }^{\circ} \mathrm{C}\left(\mathrm{EtOH}-\mathrm{H}_{2} \mathrm{O}\right) . \mathrm{NMR}$ data: $\delta \mathrm{H}\left(\mathrm{CDCl}_{3}\right) 7.01$ (d. $10.2 \mathrm{~Hz}, 2 \mathrm{H}), 6.35$ (10.2 Hz, $2 \mathrm{H}$ ), 3.30 (br q, J = 7 Hz, $2 \mathrm{H}$ ), 3.11 (br q, J = 7 Hz, $2 \mathrm{H}$ ), 1.46 (s, 3H), 1.02 (2 overlapping quartets, $\mathrm{J}=7 \mathrm{~Hz}, 6 \mathrm{H}) . \quad \delta \mathrm{C}\left(\mathrm{CDCl}_{3}\right)$ 184.5, 167.1, 151.8, 128.7, 50.2, 41.5, 41.1, 26.4, 14.6, 12.5. IR data: $\mathrm{cm}^{-1}$ (film) 2973, 2935, 1675, 1655, 1460, 1423, $1405,1377,1359,1317,1276,1252$, 1222, 1186. 1150, 1101, 1084, 1045, 1014, 942, 906, 866, 785, 768. 736, 702, 667. 583. 538, 460. Anal. Calcd. for $\mathrm{C}_{12} \mathrm{H}_{17} \mathrm{NO}_{2}$ : C, 69.54\%; H, 8.27\%; N, 6.76\%. Found: C, 69.24\%, H, 8.02\%, N, $655 \%$.

Acid catalyzed fragmentation of dienones $\mathbf{6 b}$ and $6 \mathbf{c}$. A portion of thiocarbethoxy dienone $\mathbf{6 b}$ (20.7 $\mathrm{mg}, 0.104 \mathrm{mmol}$ ) was stirred for $2 \mathrm{~m}$ in $17.9 \% \mathrm{H}_{2} \mathrm{SO}_{4}$. Extraction via the ether method yielded $15.6 \mathrm{mg}$ of product. The ${ }^{1} \mathrm{H}$ NMR spectrum revealed only p-cresol. NMR data, $\delta$ $\left(\mathrm{CDCl}_{3}\right) 7.01(\mathrm{~d}, \mathrm{~J}=8.0 \mathrm{~Hz}, 2 \mathrm{H}), 6.72(\mathrm{~d}, \mathrm{~J}=8.0 \mathrm{~Hz}, 2 \mathrm{H}), 2.25(\mathrm{~s}, 3 \mathrm{H})$. Similar acid treatment of $\mathbf{6 c}$, after $1 \mathrm{~h}$, also yielded only p-cresol.

\section{References}

1. For reviews of carbocationic rearrangements, see (a) Saunders, M.; Chandrasekhar. J.; Schleyer, P. v. R. In Rearrangements in Ground and Excited States; de Mayo, P.; Eds. Academic Press, New York, 1980; Vol 1. p 1. (b) Sorensen, T. S.; Rauk, A. Pericyclic Reactions Marchand, A. P.; Lehr, R. E. Eds.; Academic Press: New York, 1977; Vol. $2,1$. (c) Bethell, D. Reactive Intermediates: A Serial Publication Jones, M.; Moss, R A. Eds., Wiley: New York, 1978; Vol. 1. (d) Bethell, D.; Gold, V. Carbonium Ions, an Introduction. Academic Press: London, 1967, p 204. (e) Olah, G. A.; Schleyer, P. v. R., Eds. Carbonium 
Ions, Wiley Interscience: New York, 1968; Vol. 1-5. (f) Miller, B. Mechanisms of Molecular Migrations Thyagarajan, B. S. Ed., Interscience: New York, 1968; Vol. 1, 247. (g) Vogel, P.; Carbocation Chemistry, Elsevier, New York, 1985, 323.

2. For a review of MT values, see Shubin, V. G. Topics Curr. Chem. 1984, 117, 267.

3. Stiles, M.; Mayer, P. J. Am. Chem. Soc. 1959, 81, 1497.

4. Marx, J. N.; Argyle; J. C.; Norman, L. R. J. Am. Chem. Soc. 1974, 96, 2121.

5. Marx, J. N.; Bombach, E. J. Tetrahedron Lett. 1977, 2391.

6. Marx, J. N.; Hahn, Y. S. P. J. Org. Chem. 1988, 53, 2866.

7. Marx, J. N., Zuerker, J. C.; Hahn, Y. S. P. Tetrahedron Lett. 1991, 1921.

8. Merken, H. M.; Merken, C. D.; Hong, Y. L. V.; Hahn, Y. S. P.; Marx, J. N. manuscript in preparation.

9. House, H. O; Ryerson, G. D. J. Am. Chem. Soc. 1961, 83, 979 and earlier papers quoted therein.

10. Cann, P. F.; Howell, D.; Warren, S. J. Chem. Soc., Chem. Commun. 1971, 1148.

11. Carrupt, P. A.; Vogel, P. J. Phys. Org. Chem. 1988, 1, 287.

12. Wemple, J.; J. Am. Chem. Soc. 1970, 92, 6694.

13. Dagli, D. J.; Gorski, R. A.; Wemple, J. J. Org. Chem. 1975, 40, 1741.

14. Butke, G. P.; Jimenez, F.; Michalik, J.; Gorski, R. A.; Rossi, N. F.; Wemple, J. J. Org. Chem. 1978, 43, 954.

15. Danishefsky, S.; Kitahara, T. J. Am. Chem. Soc. 1974, 96, 7807.

16. Reich, H. J.; Renga, J. M.; Reich, I. L. J. Am. Chem. Soc. 1975, 97, 5434.

17. Danishefsky, S.; Yan, C. F.; Singh, R. K.; Gammill, R. B.; McCurry, P. M.; Fritsch, N.; Clardy, J. J. Am. Chem. Soc. 1979, 101, 7001.

18. Schiess, P.; Stalder, H. Tetrahedron Lett. 1980, 21, 1417.

19. Marx, J. N.; Kuhler, L J., manuscript in preparation. 